\title{
Diplomacia e interés privado: Matías Romero, el Soconusco y el Southern Mexican Railroad, 1881-1883
}

\author{
Alfredo Ávila* \\ INSTITUTO DE INVESTIGACIONES HISTÓRICAS-UNAM
}

A través de la figura de Matías Romero se analiza cómo los políticos liberales del siglo xIx creyeron contribuir

al progreso de la república fomentando el esfuerzo, la iniciativa y el enriquecimiento particular de ciertos empresarios privilegiados.

\section{INTRODUCCIÓN}

$\mathbf{M}$ atías Romero nació en 1837 en la ciudad de Oaxaca, en el seno de una familia criolla. ${ }^{1}$ Desde joven mostró interés por la diplomacia. Estudió Leyes e intentó ocupar algún puesto en la legación mexi-

* Este artículo fue realizado entre octubre de 1994 y los primeros meses de 1996 en el proyecto México en el Congreso de Estados Unidos, llevado a cabo en el Instituto Mora, con el apoyo del Consejo Nacional de Ciencia y Tecnología. Quedo muy agradecido con los miembros del seminario de becarios, dirigido por Ana Rosa Suárez Argüello y Mónica Toussaint, especialmente con Gerardo Gurza, Gabriela Pulido y cana en Londres. Su relación con Benito Juárez y otros destacados liberales lo pusieron camino a Washington en diciembre de 1859. Fue secretario de la legación y luego, en 1863 , se desempeñó por primera vez como ministro

Dolores García Pimentel. La maestra Cristina Gonzálezy Armando Correa leyeron el mecanuscrito completo y me hicieron oportunos comentarios. Durante todo este tiempo he contado con el apoyo de Dinorah Pesqueira, quien me ayudó en la transcripción de información y del texto: de alguna manera, este trabajo también es suyo, bien que sólo yo soy responsable por las fallas que pudiera tener.

1 Para los datos biográficos, seguimos a Bernstein, Matías, 1982. 
plenipotenciario. Sabemos que en Estados Unidos, Romero se relacionó con personajes muy importantes de la política (especialmente miembros del gobernante partido republicano) y de los negocios. En México estuvo también estrechamente vinculado con los políticos liberales: juaristas y después porfirianos. Además de su puesto diplomático en Estados Unidos, ocupó en tres ocasiones la cartera de Hacien. da: de 1868 a 1872 , de 1877 a 1879 y de 1892 a 1893 . Las ideas económicas $\mathrm{y}$ financieras de Romero eran las de un liberal ortodoxo: mucha iniciativa privada y poca intervención del Estado -salvo, como veremos más adelante, para fomentar a la primera. En política participó con los gobiernos liberales, lo cual no"nos dice mucho, ya que en esa época cualquiera que quisiera destacar políticamente debía proclamarse liberal. Destacamos sus negativas a secundar los pronunciamientos y rebeliones, aun si triunfaban: Romero apoyó a Díaz, sólo cuando fue electo presidente. Su visión de la política exterior estuvo fuertemente unida a sus ideas librecambistas, y siempre buscó el desarrollo económico de su país. En éstas andaba, cuando murió en Washington en 1898.

En un reciente libro, Fernando Escalante $^{2}$ nos introduce al mundo de los valores y la moral pública mexicana de la pasada centuria. El estudio de las relaciones y comportamientos sociales lleva al autor a declarar que la ciudadanía sólo estaba en la imaginación de algunos hombres. No había ciudadanos, de manera que no podemos

\footnotetext{
${ }^{2}$ Escalante, Ciudadanos, 1992.
}

exigir a los actores políticos del México decimonónico que se comportaran como tales. Según el autor, en el siglo XIX mexicano "predominan las lealtades personales y las conspiraciones, $y$ la autoridad pública es, más que otra cosa, un recurso útil para promover intereses particulares". ${ }^{3}$ No es otra la idea que del liberalismo nos ha mostrado la visión materialista de la historia: las políticas liberales tienden a acrecentar el poder de la clase burguesa. Un Estado liberal será, pues, un Estado burgués, y las decisiones tomadas por su gobierno tenderán a proteger los intereses de su burguesía. Desde este punto de vista, hay una relación clara entre la actuación política y los negocios. Romero no parece ser la excepción: durante la segunda mitad de 1880 gestionó y obtuvo una concesión del gobierno de Oaxaca para construir un ferrocarril de la ciudad de México a la capital del estado. Inmediatamente traspasó su concesión. Una serie de problemas entre los dos principales ferrocarriles del país (el Central y el Nacional) le permitió celebrar una cena en el neoyorquino restorán Delmonico's, el 11 de noviembre de 1880 , con los principales empresarios ferrocarrileros estadunidenses interesados en México, y con su amigo Ulysses S. Grant. ${ }^{4}$ De esa reunión nació el Southern Mexican Railroad, compañía que a partir de la concesión

3 Ibid., p. 52.

${ }^{4}$ Valadés, Porfirismo, 1987, t. I, p. 35; McFeely, Grant, 1982, p. 487. Ulysses Grant participó en el proyecto ferrocarrilero de Romero al mismo tiempo que en una sociedad financiera de su hijo, la Grant \& Ward. Pletcher, Rails, 1958, pp. 149-181. 


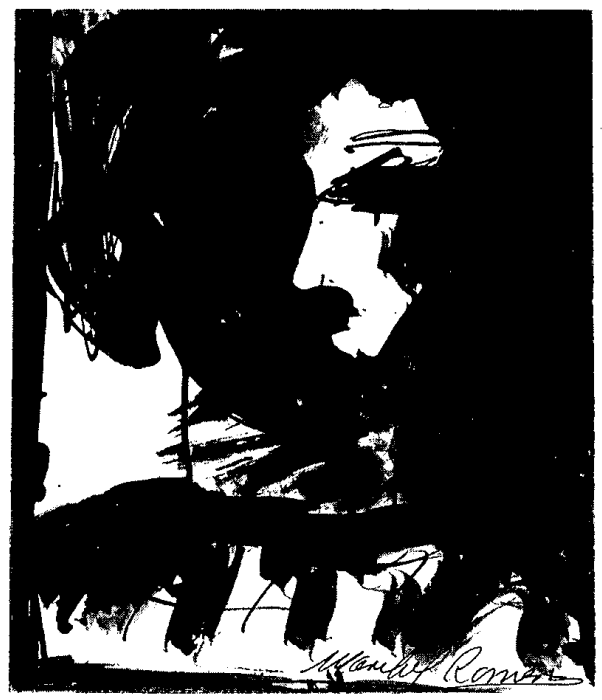

oaxaqueña proyectó la construcción de vías férreas entre México, la frontera con Guatemala, Oaxaca y ramales a Tehuantepec y Antón Lizardo. La concesión obtenida en 1881 no incluía subsidios y el proyecto fracasó. ${ }^{5}$

Esos primeros años de la década de 1880 fueron muy atareados para Matías Romero. Además del ferrocarril, se encargó de las negociaciones entre México y Estados Unidos acerca del paso de tropas por la frontera en persecución de indios bárbaros. El presidente González tuvo que recurrir a su experiencia para evitar la injerencia estadunidense en los problemas de límites entre México y Guatemala. También fue 1881.

${ }^{5}$ Concesión, Diario oficial, 27 de mayo de el principal promotor mexicano del tratado comercial con Estados Unidos en 1883. Lo primero que llama nuestra atención en estos hechos es la participación en ellos del general Grant, presidente del Southern Mexican Railroad. Fue uno de los firmantes del tratado comercialy, si hemos de creer a Romero, su intervención en la solución de los problemas con Guatemala fue asaz valiosa. Notamos también que uno de los límites del ferrocarril estaba en la frontera guatemalteca, por lo que suponemos que era importante solucionar el problema fronterizo para su construcción. Otrosí, al revisar la lista de productos estadunidenses que podrían pasar a México sin pagar aranceles, incluidos en el tratado de 1883 , nos enteramos de que en ellos iban los 
necesarios para la construcción de ferrocarriles, y entre los productos mexicanos de exportación libres de impuestos estaban el café, el azúcar, el tabaco y el hule. Todos ellos producidos en el Soconusco y en Oaxaca, lugares en donde Romero tenía propiedades agrícolas, y podían ser transportados por el Southern Mexican Railroad. De entrada -según nos parece-, para Matías Romero la actividad pública no era más que "un recurso útil para promover intereses particulares. ${ }^{\text {"6 }} \mathrm{Sin}$ embargo, estamos seguros de que Romero rechazaría este aserto. Como veremos más adelante, él estaba convencido de que sus actos servían a un fin público y no a un objeto particular, pero podríamos desconfiar de su discurso. Tal vez, actualmente, las explicaciones más convincentes son las que descubren móviles económicos y privados. Por lo regular, los individuos actúan eligiendo-yvalorando-opciones que les reditúen algún beneficio. Inmediatamente, podemos pensarque esos "beneficios" son de carácter económico y privado. Pero los valores cambian, y no podemos partir de ese prejuicio para estudiar el comporta. miento de los individuos de otras épocas. Quizá en nuestro caso deberíamos empezar por examinar el propio discurso de Matías Romero. Tal vez debamos desconfiar menos de los argumentos con que justificó sus propios actos. Este artículo trata precisamente de cómo los liberales como Romero creyeron poder contribuir al progreso de la república con el esfuerzo, la iniciativa y el enriquecimiento de unos cuantos.

${ }^{6}$ Loc. cit.

\section{FERROCARRILES Y PROGRESO}

Sin insistir mucho, recordaremos el programa de "libertad, orden y progreso" puesto en práctica por los politicos mexicanos después del pronunciamiento de Tuxtepec. El proyecto liberal iniciado por la generación de Juárez tenía entre sus metas secularizar a la sociedad mexicana, era anticorporativo y pretendía afianzar la supremacía del Estado frente a los distintos actores sociales. Sus principales ataques fueron dirigidos primordialmente contra la Iglesia católica y contra las posibilidades monárquicas de México. El liberalismo decimonónico tuvo, pues, su buena dosis de republicanismo. No podemos hacer menos las exigencias materiales de los liberales de la repú. blica restaurada. La desamortización de bienes corporativos tendía a favorecer a los grandes propietarios, pese a los buenos deseos de fomentar la pequeña propiedad. Sin embargo, el liberalismo de la república restaurada se caracterizó por ser más político que económico: se toleró la libertad de prensa y se afianzó una cierta visión de la historia mexicana. Los políticos más jóvenes (casi todos ellos con Díaz) pronto consideraron muy "abstracto" y dogmático al liberalismo de la época de Juárez; creían que el gobierno debía ceder frente a las urgencias materiales y alcanzar el consenso con todos los sectores de la sociedad-incluidos los conservadores-con tal de lograr el progreso. ${ }^{7}$ El régimen de Porfirio Díaz

7 Véase para el programa político de "liber. tad, orden y progreso", Hale, Transformaciones, 1991, pp. 51-111. 
no echó en saco roto las opiniones de los jóvenes intelectuales. Su gobierno logró conciliar a la mayor parte de los sectores sociales en pugna con una política de "pan y palo". Estableció así un poco de orden en el país, el cual sirvió como campo propicio para las inversiones, estimuladas por el gobierno federal a través de concesiones y subsidios. No menos importante fue la reestructuración de la política exterior, destinada a formar una imagen atractiva de México en el extranjero. ${ }^{8}$ Durante el primer periodo presidencial de Porfirio Díaz (1876-1880) y especialmente durante el "interregno" de Manuel González (1880-1884), se obtuvo la confianza de los inversionistas estadunidenses. La producción (básicamente en el sector primario) creció notablemente y fue menester su exportación. De manera que fue imperioso el establecimiento de vías de comunicación entre las zonas productoras y los mercados internos y puertos fronterizos. Las concesiones a compañías ferrocarrileras iban casi siempre acompañadas de subsidios, que hacían más atractiva la inversión en México. No hace falta recordar, además, que el ferrocarril era el símbolo del progreso. En nuestro país, a la larga, los ferrocarriles permitieron la integración del territorio nacional y propiciaron el crecimiento de diversos sectores productivos; aunque este "crecimiento desde fuera" (con capitales extranjeros) no permitió el desarrollo de esos sectores. ${ }^{9}$

${ }^{8}$ Riguzzi, "México", 1988, pp. 137-151.

9 Sobre el inicio del régimen de Díaz: Katz, "República", 1994, pp. 159-245 (pp. 177-187).
En Estados Unidos, el Norte había terminado imponiéndose a los sureños, de manera que se vivió durante la Reconstrucción un notable crecimiento industrial, ejemplificado por el tendido de vías férreas. Los grandes empresarios estadunidenses de la segunda mitad del siglo XIX estuvieron muy pronto en condiciones de invertir en el exterior, y México se ofrecía como un campo propicio. No resulta extraño, entonces, que Matías Romero, ministro mexicano en Washington durante tantos años, fuera una pieza clave en la canalización de inversiones estadunidenses en México. Tenía de su parte los vínculos que había logrado establecer con los republicanos en la época de la guerra de Secesión. Muchos de esos republicanos, sin abandonar la política, se habían convertido en empresarios. También ocurrió que empresarios se convirtieran en políticos para defender sus intereses. Incluso, llegó un momento en que al Senado se le llamó Club de los Millonarios, por estar representados allí los intereses empresariales en lugar de los intereses de los estados. ${ }^{10}$ Una situación así resultó favorable para la corrupción, especialmente en el partido gobernante, aunque los demócratas no quedaron exentos: empresarios muy importantes, como el ferrocarrilero Jay Gould, estaban vinculados con ellos.

Matías Romero conoció $-\mathrm{y}$ de su correspondencia particularse desprende que trató- a empresarios como

Acerca de los ferrocarriles y el crecimiento económico Coatsworth, "Impacto", 1992, pp. 178-208.

${ }^{10}$ González, "Reconstrucción", 1988, t. 9, pp. 11-117. 
William Dodge, Hiram Barney y Jay Gould, y a políticos como Ulysses S. Grant, y el general E. O. C. Ord. Fue testigo de la formación de las grandes fortunas de algunos de estos hombres y de la riqueza que éstas generaban para Estados Unidos. Ciertamente no se vivía una edad de oro pero sí de oropel, como se la llamó. Los políticos mexicanos presenciaron el rápido desarrollo de la industria en Estados Unidos durante la Reconstrucción y de las posibilidades que ésta abría para México. Los ferrocarriles y la infraestructura debieron impresionar al diplomático Matías Romero, pues en adelante siempre insistió en el tendido de vías férreas y cables telegráficos como conditio sine qua non para el progreso nacional. Vio claramente la oportunidad de exportar materias primas al industrial vecino del norte. Para producirlas, consideró importante desarrollar las condiciones y la infraestructura necesarias en México, un paísque, como casi toda América Latina, se había debatido en medio siglo de luchas intestinas y crónicos problemas financieros.

La minoría rectora del país proyectó en diversas regiones el crecimiento material, imprescindible para el progreso mexicano. Romero pensó en el sudeste del país como un campo propicio para experimentar sus proyectos progresistas. De enero de 1868 a junio de 1872 ocupó la Secretaría de Hacienda y desde allí promovió el desarrollo del Soconusco. Se aprovechó de los poderes extraordinarios que por entonces tenía el presidente Juárez para comprar una embarcación en Estados Unidos, destinada a la costa chiapaneca. También ordenó comprar rifles Spencer estadunidenses para armar a las guarniciones fronterizas del sur. Presentó al Congreso una serie de propuestas -que fueron aprobadaspara habilitar un puerto al comercio extranjero en la costa soconusqueña; para celebrar contratos con compañías de vapores, construir un camino del Soconusco a México y tender cables telegráficos en aquella región y otros puntos. ${ }^{11}$ Propuso también que se diera protección a los extranjeros de Chiapas (recordemos la importancia que por entonces adquiría la inmigración alemana), y para que los artículos guatemaltecos entraran libres de impuestos a Chiapas, y desde allí exportarlos; también pidió que se estimulara la exportación de productos agrícolas soconusqueños. ${ }^{12}$

Romero complementó su actividad pública con la privada. Desde 1871 planeaba un lugar para hacerlo prosperar, enriquecerse e iniciar el crecimiento económico nacional. Como vimos, Soconusco fue su elección. Después de salir de la Secretaría de Hacienda, poco antes de la muerte del presidente Juárez, decidió viajar al sur, a su tierra prometida. Antes, hizo escalas en Veracruz, Yucatán y Tabasco. Después elogiaría los avances agrícolas de esos tres estados. Chiapas, en cambio, le pareció una tierra riquísima y totalmente desperdiciada hasta ese momento, es decir, ideal para su experimento progresista. Dedicó los siguientes años a intentar sacar frutos -literalmente- del gran potencial del

11 Romero hizo un resumen de sus actividades en favor del Soconusco como secretario de Hacienda; Romero, Expediente, 1871.

12 Ibid., pp. 145 y ss. 
sudeste. Adquirió algunas fincas y denunció varias tierras baldías. Se interesó principalmente en el cultivo del café en su propiedad, el Cafetal Juárez. También se hizo dueño de una finca llamada El Bejucal, la cual le acarrearía muchos problemas, pues se encontraba en tierra que, a ciencia cierta, nadie sabía si pertenecía a Chiapas o a Guatemala. ${ }^{13}$ La visión del progreso que Romero tenía para México era la producción de materias primas. Si bien el proyecto económico del porfiriato no dejó de lado el desarrollo industrial, próspero ya desde entonces en el noreste del país, prefirió la explotación de las riquezas naturales. ${ }^{14}$

Cuando llegó a Chiapas, Romero estableció amistad con el dueño de EI Malacate, Justo Rufino Barrios, antiguo caudillo liberal de Guatemala y, en ese momento, su presidente. Sin embargo, los problemas que tuvo en El Bejucal con indios de aquel país pronto lo enemistaron con el general Barrios. El "finquero" mexicano creía, y es muy probable que así fuera, que el presidente guatemalteco estimulaba a los indios para destruir sus propiedades. Aunque también es cierto que nunca supo comprender las añejas formas de explotación y trabajo en

\footnotetext{
13 Para la aventura en el Soconusco, Cosío, "Aventura", 1958, pp. 35-59.

14 Gerardo Gurza me ha sugerido incluso, que la visión del progreso nacional de Matías Romero se parecía mucho al de una "República bananera". Para comprobar este aserto podemos recordar un artículo de Romero titulado sugerentemente: "Mexico: a country of Central America",Journal of the American Geographical Society, núm. 26, 1894, pp. 32-37 (citado en Thomas y Ebba Schoonover, Mexican Lobby, 1986, p. 177).
}

Chiapas, con su crónica falta de mano de obra-paliada a veces con la llegada de campesinos guatemaltecos de la sierra - y las relaciones caciquiles de los notables locales, de uno y otro lado de la frontera. Desde el punto de vista regional, Matías Romero perteneció a un nuevo grupo de propietarios en Chiapas, más preocupados por desarrollar modernas formas de explota. ción de la tierra que en seguir mante. niendo los tradicionales, pero poco productivos, sistemas de control social. Tiempo después, hacia el inicio de la década de 1890 , esta nueva elite, en alianza con el poder central, lograría consolidarse en la región, en contra de los tradicionales caciques. ${ }^{15}$

El temor a los ataques de indígenas hicieron que Romero considerara necesario armar esa zona de la frontera, lo cual sólo propició más problemas. Barrios lo acusó del intento de provocar una guerra entre las dos naciones y en el departamento guatemalteco de San Marcos había una orden de arresto contra el liberal mexicano. De todos estos problemas nació seguramente su interés por establecer, lo más pronto posible, los límites oficiales entre ambas naciones; interés que sólo generó más descontento en algunos de los dirigentes centroamericanos. Prácticamente, Matías Romero salió huyendo del Soconusco, por el temor de perder la vida a manos de hombres pagados por Barrios. ${ }^{16}$

El prestigio ganado por Romero como cercano colaborador de Juárez y las relaciones que tenía con diversos

15 Benjamin, Camino, 1980, pp. 47-53.

16 Cosío, "Aventura", 1958, pp. 35-59. 
políticos a nivel nacional y local, le valieron su eleción como diputado por el Soconusco y Tapachula al Congreso de la Unión. El 8 de abril de 1875 dejó las tierras chiapanecas y llegó, 21 días después, a la ciudad de México. El fracaso de su aventura en el sudeste no fue motivo suficiente para alejarlo de su proyecto de desarrollar aquella región. Como diputado promovió varias propuestas en beneficio del Soconusco. Insistió especialmente sobre la aprobación de presupuestos necesarios para realizar los proyectos que ya antes, como secretario de Hacienda, había llevado a las Cámaras. Sugirió el establecimiento de juzgados en Tapachula y de una aduana, para evitar el contrabando de artículos guatemaltecos que se consumían en Chiapas. ${ }^{17}$ Sin embargo, su principal preocupación como diputado fue fijar clara y permanentemente los límites con Guatemala. Su experiencia en El Bejucal, las continuas invasiones de indígenas guatemaltecos (dirigidos por sus alcaldes y gobernadores) y, ciertamente, los intentos chiapanecos de empadronar poblaciones centroamericanas, lo habían convencido de que "la necesidad primordial de Soconusco es la celebración de un tratado de límites con Guatemala". ${ }^{18}$

Por la misma época, escribió algunos trabajos acerca de los beneficios de diversos cultivos en México. Del 12 de diciembre de 1872 data su Importan-

17 Romero, "Refutación”, 1992, pp. 157-225. Originalmente fue impreso en México por la Imprenta Políglota delC. Ramiro Ponce de León, 1876.

18 Carta de Romero a Andrés Clemente Vázquez, Tapachula, 15 de septiembre de 1873, en ibid., p. 167. cia del cultivo del hule en el porvenir de la república. ${ }^{19}$ Se trata de un completo estudio botánico, agrícola y económico acerca de la explotación de ese recurso. En el Soconusco, el hule se extraía de árboles silvestres, por lo que su producción era mínima. Matías Romero se propuso aportar algunas ideas para aumentar su productividad, aunque se consideraba "enteramente profano en la materia":

Mi deseo -escribió- al llamar la atención de mis conciudadanos hacia la explotación de una fuente de riqueza que, no lo dudo, asegurará su porvenir en pocos años, es el único móvil que me ha determinado a escribir estas líneas. ${ }^{20}$

Por cierto, el cultivo del hule no aseguró su porvenir, lo cual no impidió que Romero reeditara su opúsculo en dos ocasiones más. Al igual que otros inversionistas en el país, estaba interesado en aumentar la rentabilidad aun a costa de romper los viejos sistemas productivos y de control social. Su objetivo primordial era intensificar la producción de las materias exportables y aumentar las ganancias. Sin embargo, como hombre público, también se interesó en difundir sus conocimientos. Otra obra suya, reeditada varias veces, la escribió en Tapachula en 1874, y fue publicada en el periódico El Porvenir de México. El cultivo del café en la costa meridional de Chiapas vio la luz pública otra vez en El Correo del Comercio de mayo y junio de 1875 y editado como

19 La tercera edición es de la Secretaría de Fomento, México, 1898. Puede consultarse en Textos, pp. 387.423.

${ }^{20}$ Ibid., p. 388. 


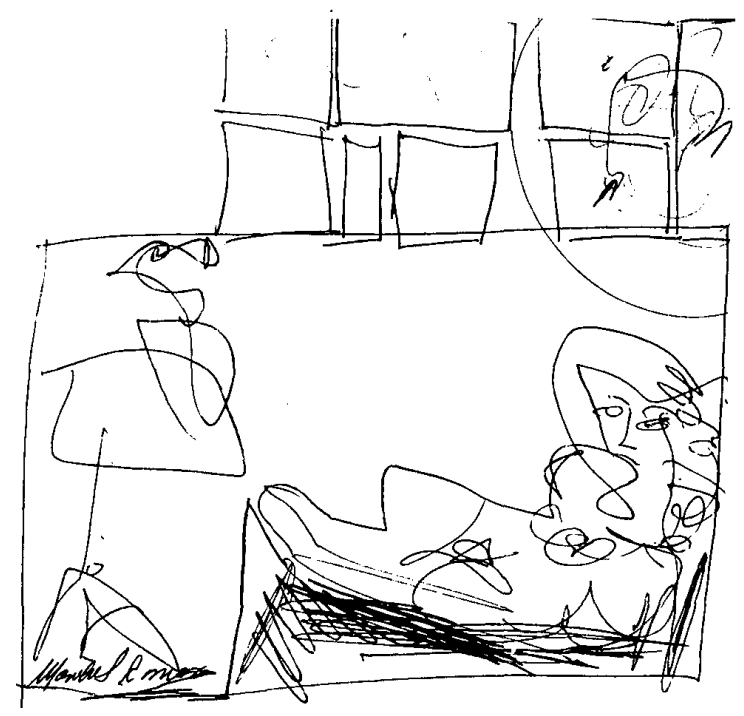

libro en agosto de ese año, cuando Romero había dejado su empresa soconusqueña. Su razón para publicarla era promover el desarrollo del cultivo del café en la región donde él había sido cafetalero. Romero estaba convencido de que cuando se hubiera desarrollado ese cultivo "hará el bienestar de una parte considerable de su territorio"21 -y de la república. Para él, y podríamos extender esta consideración a los demás liberales de la época, el progreso económico llevaba aparejado el desarrollo en todos los órdenes. La riqueza -producto del progreso material-fomentaría los niveles de vida de los explotados trabajadores (vid. infra nuestras conclusiones) e

${ }^{21}$ Romero, Cultivo, 1875. inclusive lograría que los indígenas, hasta entonces encerrados en sus comunidades, se convirtieran en verdaderos ciudadanos. Romero consideraba que el cultivo de café fomentaría la pequeña propiedady, de tomarse ciertas medidas "compatibles con las prevenciones de la Constitución", podrían integrarse los indígenás a la fuerza de trabajo. Creía que esto sería tan provechoso para ellos como para la república. La explotación de los recursos naturales del país (como el café) enriquecería a los grandes inversionistas y a los pequeños propietarios y, con ello, "podría mejorar en lo absoluto la condición del país". ${ }^{22}$ Recordemos que

22 Romero, "Cultivo", en Textos, pp. 425. 469 (p. 434). 
para el liberalismo, el progreso y enriquecimiento individual (mas no egoísta) de todos los ciudadanos estaba unido al desarrollo general de la república. Lo que hoy llamamos "iniciativa privada", la feroz competencia y hasta las injusticias cometidas por la explotación capitalista eran considerados como elementos necesarios para el desarrollo común. Por eso los políticos mexicanos de la época promovían desde el gobierno la construcción de la infraestructura y la difusión de conocimientos necesarios para estimular la acción individual. Su oposición al proteccionismo estatista se basaba en la idea de que tal política beneficiaba únicamente a unos pocos obreros y a algunos empresarios y especuladores. Como ha señalado David Brading, en el enfoque de los problemas económicos del país, los liberales insistían "en el interés individual como motor principal del progreso material". ${ }^{23}$

\section{El SOUTHERn MEXICAN RAILroad, uno}

La explotación racionalizada de las riquezas mexicanas traería el anhelado desarrollo. Al menos eso creían los liberales de principios del porfiriato. Como hemos visto, el ejemplo de Estados Unidos no pasaba inadvertido para los dirigentes mexicanos del periodo y se

23 Brading, Orbe, 1991, pp. 711-712; Pocock, Machiavelan, 1975, pp. 452-505, señaló la oposición entre el republicanismo clásico y el liberalismo, pero hay que reconocer la posibilidad de un republicanismo liberal: los ciudadanosburgueses buscan su bien privado y al mismo tiempo el público, véase Hirschmann, Pasiones, 1978. aprestaron a imitarlo. Para Matías Romero, al menos, resultaba estimulante la riqueza y prosperidad alcanzada por ese entonces entre los estadunidenses: se habían recuperado del desastre económico que significó la guerra civil, redujeron los intereses de su deuda pública y habían logrado la estabilidad de su moneda. Romero consideraba que ese estado de recuperación económica se debía, en buena medida, a los ferrocarriles recién construidos:

Entre las empresas que ofrecen mayores garantías de seguridad, y réditos en este país [Estados Unidos], están las vías férreas, cuyas utilidades son por lo general de importancia, supuesto que representan una propiedad valiosa en sí, y pagan un interés sobre sus bonos del cinco al siete por ciento. ${ }^{24}$

No había duda entonces del provecho que para los inversionistas estadunidenses tenían los ferrocarriles. No podía ser distinto para México, sobre todo si se consideraba que los ferrocarriles mexicanos eran vistos por los estadunidenses como extensión al sur de su propia red férrea. Ciertamente, las ganancias producidas por los ferrocarriles serían para los inversionistas -casi todos extranjeros-, pero habría otros beneficios para México. Los productores nacionales - como Romeropodrían exportar a través de la vías tendidas con Estados Unidos, los frutos de las tierras mexicanas. La construcción de ferrocarriles - escribía Romero al general Grant- permitiría "la extracción de nuestros productos sin los fuertes recargos de fletes que aho-

${ }^{24}$ Romero, Informe, 1881, p. 4. 
ra sufren". Por esto, los productores mexicanos representados por él pedían que los empresarios estadunidenses cooperaran con ellos para construir vías en México y lograr el "enlace de las líneas de las dos repúblicas".25 El general Grant respondió favorablemente a las propuestas de Romero. Inclusive, fue más allá al sugerir la formación de un "sindicato" o una gran corporación de empresarios "capaz de construir desde luego un gran sistema de ferrocarriles a través del país" ${ }^{26}$

Ya hemos comentado que Romero no sólo hacía propuestas para el desarrollo de la república, sino que las llevaba a la práctica. Con el ánimo empresarial tan típico de los políticos estadunidenses de la época -y ya también de los mexicanos-planeó la construcción de un ferrocarril en el sur del país. Consiguió que el gobernador de Oaxaca, general Francisco Mejueiro (también puede aparecer como Mexueiro) se interesara en el proyecto de un ferrocarril que pasara por la ciudad capital de aquel estado y uniera las bahías de Huatulco y de Antón Lizardo. Para lograr esto, el gobernador oaxaqueño debería pedir una concesión federal y en ese momento, según Romero, "el presidente está dispuesto a dar[la]". ${ }^{27}$ De hecho, don Matías logró

${ }^{25}$ Carta de Matías Romero a Ulysses S. Grant, México, 16 de marzo de 1880, "Archivo Particular de Matías Romero" (AMR), Copiadores, vol. 37, fojas 268-270.

${ }^{26}$ Carta de Ulysses S. Grant a Matías Romero, Galena, Illinois, 21 de junio de 1880, AMR, Correspondencia, doc. 29828.

${ }^{27}$ Carta de Romero al general Francisco Mejueiro, México, 2 de julio de 1880, AMR, Copiadores, 37, $423 \mathrm{~A}$. Romero propuso al goberna- involucrar al general Díaz en el proyecto de un "sistema de ferrocarriles internacionales y mexicanos", junto con el general Grant. ${ }^{28} \mathrm{El} 25$ de agosto de 1880 obtuvo del gobernador de Oaxaca una concesión sin subsidio para tender vías en el estado. Ése fue el primer paso para la prosecución del sueño de Romero: un sistema ferroviario que integrara todas las regiones productivas del país-inclusas las sureñascon la frontera entre México y Estados Unidos. Mejueiro otorgó a Romero autorización para formar una compañía que se encargara de la construcción del ferrocarril el 3 de septiembre, y unos días después lo autorizó a traspasar la concesión del 25 de agosto. ${ }^{29}$

Para lograr su objetivo, Romero viajó en octubre de 1880 a Nueva Orleans. Publicó en distintos diarios de aquella ciudad algunas consideraciones acerca del estado de la república y trabajó, con Ulysses Grant, en una campaña en pro de la inversión en México. A la sazón, el viejo general se encontraba en gira proselitista en favor del candidato republicano James Garfield. En uno de sus discursos, del 13 de octubre

dor que nombrara un agente para conseguir la concesión, obviamente pensaba en sí mismo.

${ }^{28}$ Carta de Porfirio Díaz a Ulysses Grant, México, 9 de junio de 1880, AMr, Copiadores, 37, 390. Entre los copiadores de Romero aparece correspondencia de personajes vinculados con él.

${ }^{29}$ Carta de Romero a Mejueiro, México, 7 de septiembre de 1880, AMR, Copiadores, 37, 423a. Con estas autorizaciones, Romero creía poder convencer a los inversionistas estadunidenses para hacer un reconocimiento del terreno y un estudio inicial que costaría, según apreciaba, alrededor de 20000 pesos (carta de Romero a Mejueiro, México, 16 de septiembre de 1880, AMR, Copiadores, 37, 423a). 
en Boston, Grant elogió especialmente la situación propicia de México para la inversión extranjera. Destacó las ventajas de la construcción de vías férreas en el país del sur, conectadas con la red estadunidense. Los ferrocarriles permitirian comprar a los estadunidenses -con indudables beneficios-hasta 200 millones de dólares anuales de frutos tropicales a México, en lugar de comprarlos a otras naciones, como Cuba y Brasil, que además de los gastos de los fletes marítimos, eran países donde existía la esclavitud y no se regían por el sistema republicano. ${ }^{30}$

El 11 de noviembre de 1880, Matías Romero se reunió en Nueva York con algunos empresarios estadunidenses, muchos de ellos amigos personales suyos. Esa noche ofreció una cena en el restorán Delmonico's, a la que asistieron, entre otros, Ulysses Grant, William Dodge (del Pacific Railway), Adams (del Ferrocarril Central y del de Sonora) y Woerishsoffer (de la Compañía Constructora Nacional). La finalidad era constituir una compañía que reuniera todos los intereses ferrocarrileros en México y formar un gran sistema único, que comunicara, como hemos dicho, las principales zonas productoras del país con la red ferrocarrilera estadunidense. Se acordó formar una comisión que considerara el asunto, cuya presidencia ocuparía Grant, la cual dictaminaría el 18 de noviembre en la casa del empresario Thomas Huntington. Matías Romero fue nombrado segundo miembro de la comisión. Después de varias reuniones las compañías concesionadas de-

${ }^{30}$ Romero, Informe, 1881, p. 9. cidieron no actuar de común acuerdo, si bien se interesaron en la nueva compañía encargada de construir el ferrocarril de Oaxaca. ${ }^{31}$

El mes de marzo de 1881 se organizó la compañia del Mexican Southern Railroad (conocido en México como Ferrocarril Meridional Mexicano) en Nueva York. Sus miembros, aprovechando la presencia que tenían en la legislatura local, lograron que el $17 \mathrm{de}$ ese mes fueran aprobados los dos artículos que le daban vida legal. El día 24 quedó definitivamente organizada la compañía: la presidencia fue de Ulysses Grant; Dodge fue vicepresidente; James Work, secretario; Russell Sage, tesorero; y la junta directiva quedó integrada por Jay Gould, Frank Work y el propio Sage. El capital inicial de la empresa se fijó en un millón de dólares, aunque sólo se cobró en principio el $10 \%$ de la suscripción. Según el presidente de la compañia, ésta tenía por objeto:

Hacer del ferrocarril de Oaxaca la prolongación de las líneas que vienen a esta capital [México] de la frontera de México con Estados Unidos, para formar así una troncal que tenga en comunicación a todo este país entre sí y con Estados Unidos y a América Central con México y Estados Unidos. ${ }^{32}$

Es decir, se planteó la posibilidad de que la compañía no se limitara a Oaxaca, sino incluso que se extendie-

31 Ibid., pp. 19-26.

32 Ulysses S. Grant, "Al presidente de los Estados Unidos Mexicanos", [sin fecha, pero se infiere que es del 14 de abril de 1881 y escrita en la ciudad de México], AMr, 37, 596 y ss.; también, Romero, Informe, 1881, pp. 37-40. 
ra la construcción hasta el sudeste, ante la frontera misma de Chiapas y Guatemala. Esto beneficiaría a los productores agrícolas de aquella región. Es más, dado que Matías Romero no vendió las tierras que había adquirido en el Soconusco, quizá esperaba, por fin, hacerlas producir y exportar. Como recordamos, desde la Secretaría de Hacienda, desde el Soconusco y desde el Congreso de la Unión había intentado desarrollar la infraestructura suficiente para fomentar la producción y exportación de frutos agrícolas del sudeste. Sus problemas con los indigenas de la sierra guatemalteca, que bajaban a buscar trabajo a Chiapas, y con el sistema caciquil imperante en la zona lo habían hecho fracasar por el momento. Pero ¿qué mejor manera de colaborar en el desarrollo de la región y de sus cafetales y fincas que la construcción de un ferrocarril? Sin duda, éste permitiría una explotación más racional de los ricos recursos del sudeste y, de paso, permitiría un mejor control de la zona. Por esto, se hacía menester una nueva concesión y a ese efecto viajaron Romero y Grant a la ciudad de México. Se realizó un contrato con el poder ejecutivo, encargado al general Manuel González, y a los pocos días se llevó al Congreso. El contrato establecía una concesión para la construcción de un ferrocarril, sin subsidios: idea básica en el pensamiento antiproteccionista de Matías Romero, que, por necesidades prácticas no fue empleada por los políticos del porfiriato; como la experiencia demostraría pronto, las concesiones ferrocarrileras sólo tenían éxito cuando eran acompañadas de jugosos sub- sidios estatales y/o federales. Las vías férreas de la compañía irían de la frontera de Guatemala a la ciudad de México, pasando por Tehuacán y Puebla. Tendría ramales que, a través de la ciudad de Oaxaca, llegarían hasta Huatulco en el Pacífico, y Antón Lizardo en el Golfo de México. Es de notar que las tarifas autorizadas al Ferrocarril Meridional eran más altas que las permitidas a los otros concesionarios, no tenía representantes gubernamentales en la junta directiva y ni siquiera se hablaba de la presencia de un inspector federal en su construcción. El 13 de mayo de 1881 en el Congreso de la Unión, salieron a relucir estos puntos, lo cual provocó un debate. La comisión de Fomento de la Cámara de Diputados, luego de entrevistarse con Grant, defendió el contrato como un "proyecto de tan innegable importancia" para el engrandecimiento y desarrollo del país. Unos días después, el 16, el diputado Manuel Payno -quien también estaba interesado en algunas empresas en el Golfo- defendió concluyentemente el contrato, aduciendo que las variantes, tanto en las tarifas como en la presencia de representantes e inspectores del Gobierno, obedecían a que el Ferrocarril no tenía subsidio oficial, por lo cual no era necesaria su presencia para defender los intereses gubernamentales. Finalmente, se aprobó el contrato con una ligera modificación: todos los resguardos del ferrocarril estarían compuestos por ciudadanos mexicanos por nacimiento. ${ }^{33} \mathrm{La}$ aprobación por el

33 Diario de los Debates, 1881, t. II, pp. 564 . 565 y $595-619$. 
Senado no ocasionó mayores contratiempos y, según apreciaba Romero, "los trabajos del ferrocarril comenzarán dentro de tres meses y el ferrocarril quedará concluido para diciembre de $1883 " .34$

Entre otras cosas, el contrato comprometía a la compañía a hacer un reconocimiento del terreno en un máximo de seis meses, contados a partir del 27 de mayo de 1881 , fecha de la publicación del contrato en el Diario Ofi. cial. En noviembre de ese año debía iniciarse la construcción, y para noviembre de 1883 , debía estar construido un mínimo de $50 \mathrm{~km}$ de vías y 100 $\mathrm{km}$ para el año siguiente. A partir de 1885 se debían construir $150 \mathrm{~km}$ anua les hasta terminarlo. La empresa se consideraría mexicana, con todo lo que eso significaba: dirimir sus problemas en los tribunales nacionales, tener domicilio en la ciudad de México (aunque se permitían filiales en el extranjero), abrir la venta de acciones a inversionistas mexicanos y no enajenar el ferrocarril a ningún gobierno extranjero. Se dejaba claro que las líneas telegráficas, vías, terrenos y demás materiales serian propiedad exclusiva de la compañía. En 99 años (es decir, en 1980) el gobierno mexicano podría adquirir el ferrocarril y, en caso de arrendarlo, lo haría al Southern Mexican Railroad.

Matías Romero había logrado, en principio, su cometido: formar la compañía:

He logrado formar una compañía -es-

${ }^{34}$ Carta de Romero a Mejueiro, México, 24 de mayo de 1881, AmR, Copiadores, 37, 423a. cribía con orgullo- más poderosa que muchas de las principales de aquí [de Estados Unidos], y he obtenido que esta compañía acepte la concesión antes de hacer ningû̉ reconocimiento preliminar. Estoy, pues, satisfecho del resultado y creo haber cumplido con mi deber en este caso. ${ }^{35}$

\section{LA DIPLOMACIA}

Ya hemos visto cómo en la promoción externa de México, la diplomacia porfirista jugó un papel muy importante. Matias Romero fue, sin duda, uno de los actores principales en la construcción de la imagen adecuada para atraer las inversiones extranjeras a México. El inicio del régimen de Manuel González heredó algunas dificultades de la primera presidencia de Díaz. Su gobierno ya no conoció el peligro del desconocimiento externo, pero sí tuvo que hacer frente a algunas prioridades diplomáticas. Desde inicios de 1881, las tropas estadunidenses pasaban la frontera con México en persecución de indios bárbaros y gavillas de asaltantes, lo cual provocó muchas protestas del lado mexicano y declaraciones prepotentes de algunos militares estadunidenses. El presidente González se vio precisado a solucionar ese problema. También se presentó la oportunidad de firmar un nuevo tratado de comercio con Estados Unidos. Y, sobre todo, se debía atender urgentemente al problema de la injerencia del recién electo gobierno de James Garfield en Ios problemas de límites entre México y Guatemala. El gobierno estadunidense dirigido por el secre-

35 Romero, Informe, 1881, p. 41. 
tario de Estado, James Blaine, intentaba consolidar su hegemonía en la región istmeña frente a la política exterior mexicana, agresiva ante los intentos guatemaltecos de unificación centroamericana. El ministro plenipotenciario de México en Estados Unidos, Manuel de Zamacona, trató de llegar a diversos acuerdos con el gobierno estadunidense acerca de estos problemas, sin embargo, el presidente Manuel González y el secretario de Relaciones Exteriores, Ignacio Mariscal, se vieron obligados a llamar a Matías Romero (aunque parecía que no llevaba buenas relaciones con el general González) dada su enorme experiencia diplomá. tica en Washington y los vínculos que con diversos políticos republicanos había establecido desde la época de la guerra civil.

Cuando avisaron a Romero, su comisión no le gustó mucho. Ya antes había tenido problemas con el presi. dente guatemalteco y prefería seguir dedicándose a sus negocios privados. Aunque fue quizá precisamente el arreglo de algunos asuntos de la compañía lo que lo decidió a ir a Estados Unidos como ministro. En enero de 1882 todavía tenía algunos asuntos que atender en México, pero esperaba salir pronto a Nueva York para "abreviar estos trabajos [los de la compañía] y facilitar la adquisición de fondos para la construcción del camino". ${ }^{36}$ Recordemos también que si uno de los límites del ferrocarril era la frontera con Guatemala, convenía que estuviera fijada.

36 Carta de Matías Romero a Porfirio Díaz, México, 15 de enero de 1882, Archivo Porfirio Díaz, leg. 7, caja 1, doc. 50.
Sin remontarnos a rastrear los antecedentes desde la colonia y especialmente desde el imperio iturbidista, recordemos que los límites entre Chiapas y la República de Centroamérica, luego Guatemala, no estuvieron establecidos claramente durante casi todo el siglo XIX, no obstante los intentos para fijarlos en distintas ocasiones. Especialmente había problemas para reconocer una línea entre el departamento chiapaneco del Soconusco y el de San Marcos en Guatemala. ${ }^{37}$ Ya hemos visto cómo para los intereses de Romero en Chiapas, esa indefinición resultó negativa y cómo consideró que, para lograr desarrollar la producción de la región, era necesario solucionar los problemas fronterizos entre ambas naciones.

La indefinición en los límites entrambas naciones provocaba serios conflictos: No resultaba extraño que autoridades municipales mexicanas integraran en sus censos a poblaciones guatemaltecas, ni que hubiera indígenas guatemaltecos dirigidos por sus alcaldes, asaltando fincas y pueblos chiapanecos. En varias ocasiones, los mojones y señales fronterizas fueron removidos con el fin de apropiarse de más territorio, por ambas partes. El gobierno de Manuel González intentó poner freno a estos problemas, por lo que movilizó "una fuerza respetable" hacia Chiapas,

${ }^{37}$ Hasta la fecha la más completa historia diplomática México-Guatemala es la de Zorrilla, Relaciones, 1984. Una visión general, pero muy completa, de los problemas de límites con Guatemala, está en Sepúlveda, "Historia", 1958, pp. 145.174. 
tanto para impedir y sofocar cualquier levantamiento de indígenas, como para proveer a otras emergencias: las agresiones cometidas por individuos procedentes de la vecina República de Guatemala. ${ }^{38}$

Sin embargo, estas demostraciones de fuerza resultaron contraproducentes para los empeños del presidente González. El gobierno del general Justo Barrios, a través del ministro estadunidense en Guatemala, Cornelius Logan, incitó al secretario de Estado de Estados Unidos a intervenir en el asunto. Según Logan, el gobierno guatemalteco estaba tan alterado por una eventual invasión de México a su territorio, que incluso estaba dispuesto a ceder el Soconusco (o el derecho que creía tener sobre ese departamento) a una potencia extranjera, entiéndase europea. ${ }^{39}$

El Departamento de Estado de Estados Unidos actuó inmediatamente. Envió instrucciones a su ministro plenipotenciario en México, Phillip Morgan, para que informara al secretario de Relaciones Exteriores, Ignacio Mariscal, que Guatemala había pedido formalmente la mediación de su gobierno en el problema de límites con México. ${ }^{40}$ Por supuesto, Mariscal negó la posibilidad de injerencia. En la entrevista que sostuvo con Morgan reco-

38 González, Discurso, 1881, pp. 57-66.

39 Cosío, Historia, 1983, p. 131. Más de la mitad de este volumen está dedicada al proble. ma de límites con Guatemala durante los años 1880.1883 y a la injerencia estadunidense en el asunto.

40 Instrucción de James Blaine a Phillip Morgan, Washington, 16 de junio de 1881, National Archives (NA), Instrucciones, M77. noció los problemas con Guatemala, pero insistió en la imposibilidad de realizar un arbitraje, pues ni siquiera se conocía el terreno por el cual se trazaría la línea divisoria. Ya antes, una comisión topográfica había intentado hacer una revisión de la zona, pero el gobierno guatemalteco impidió sus labores. Por ello, aún no podía establecerse claramente una línea y, por lo tanto, un arbitraje quedaba, de momento, fuera de lugar. ${ }^{41}$

El gobierno mexicano pronto aclaró su postura; en realidad México no aceptaba el arbitraje porque eso sería dudar que Chiapas (y Soconusco) fueran parte de la república. Sería un acto anticonstitucional. Como hemos comentado, el ministro plenipotenciario en Washington, Manuel de Zamacona, intentó por todos los medios disuadir al gobierno estadunidense de toda injerencia, y lo mismo hizo Ignacio Mariscal con el enviado Morgan. Sin embargo, el Departamento de Estado no cedió.

Los avatares de la política estadunidense ayudaron, en parte, a evitar su intervención en los problemas fronterizos de México con Guatemala. Como hemos mencionado, la política en Estados Unidos en la época de la Reconstrucción se fue haciendo cada vez más corrupta. Los votos eran ganados por bosses, patrones citadinos que controlaban amplias clientelas, generalmente de inmigrantes y desempleados. ${ }^{42}$ El presidente Hayes había intentado

41 Despacho de Morgan a Blaine, México, 12 de julio de 1881 (NA), Despachos, M97.

42 Para lo que sigue, Reichley, Life, 1992, pp. 143-147; McFelly, Grant, 1982, pp. 478.483. 


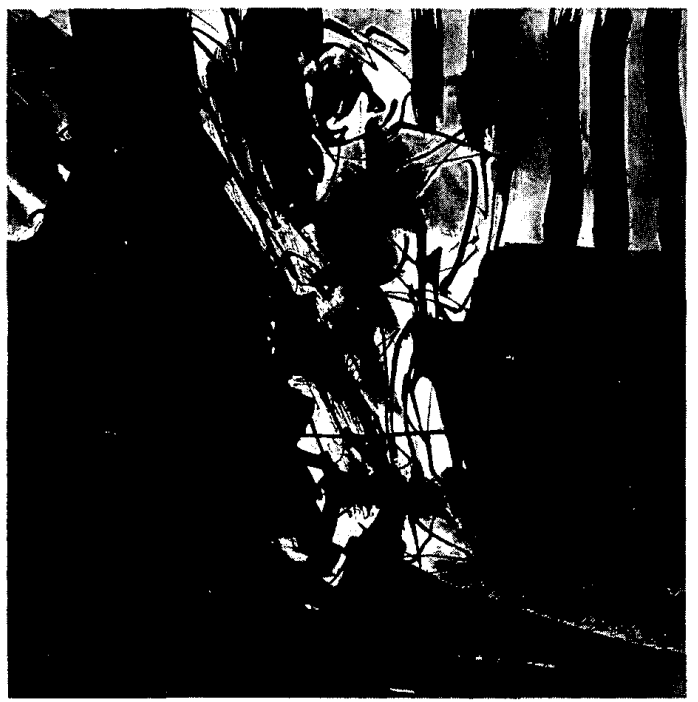

poner un freno a la corrupción, encabezada por el más importante miembro del Partido Republicano, Ulysses Grant. Hubo fuertes divisiones entre los republicanos y, durante su Convención Nacional de Chicago en 1880 , en la cual se debía elegir al candidato para la presidencia de la república, ni Ulysses Grant, ni su principal opositor, James Blaine, obtuvieron el número necesario de votos. La postulación recayó en un dark horse, ${ }^{43}$ James A. Garfield, cercano a Blaine. Tiempo después fue electo presidente, pero tuvo que aceptar en la vicepresiden. cia a Chester Arthur, un miembro de

43 Cuando los principales postulantes a alguna candidatura evitaban la nominación, solía elegirse un candidato de compromiso, llamado caballo negro. los stalwarts, grupo republicano de bosses encabezados por el general Grant. Blaine fue secretario de Estado de Garfield, pero el 2 de julio de 1881 el presidente sufrió un atentado y tiempo después murió. Al ocupar la presidencia Arthur, hubo un viraje en la política estadunidense. James Blaine abandonó el Departamento de Estado y su lugar fue ocupado por Frederick Frelinghuysen, del grupo de los stalwarts. El nuevo secretario de Estado mostraba además interés en la construcción de un canal por Nicaragua, y era hostil a los proyectos unionistas centroamericanos impulsados por el presidente Barrios. Este cambio fomentó las esperanzas de los mexicanos para solucionar los problemas con Guatemala. 
En efecto, al saberse la inminente destitución de James Blaine, el aún ministro Manuel de Zamacona supuso un cambio en la política estadunidense y en 1882, cuando su sucesor Matías Romero ya había llegado a Estados Unidos (arribó a Nueva York el 2 de marzo), consideró ganado el problema de límites, gracias al ascendente de Ulysses Grant sobre el presidente Chester Arthur. De hecho, lo primero que hizo Romero al llegar al puerto neoyorquino fue entrevistarse con su socio en el ferrocarril, el general Grant, acerca de los asuntos que iba a resolver. El viejo general se encontraba "dispuesto a ayudarnos en la realización de los proyectos" mexicanos, e incluso a darle "cartas para el presidente y el secretario de Estado que pudieran subsanar las dificultades que se presenten y que en caso necesario vendrá él personalmentea Washington" ${ }^{44}$

Los temas que Romero trataba con Grant en cada visita eran la eventual ayuda del general para solucionar los problemas diplomáticos de México con Estados Unidos y el ferrocarril. Desgraciadamente, por la cercanía y la posibilidad que tenían de visitarse, escasea la correspondencia entre los dos amigos durante los años que Romero estuvo en Washington, lo cual representa un serio obstáculo para el investigador. Sin embargo, la permanencia de Romero en Washington en la casa del propio general y la visita que éste hizo a la Casa Blanca el 27 de marzo, nos permiten conjeturar el

44 Carta de Romero a Manuel González, Washington, 8 de marzo de 1882, AMr, Copiadores, 38, 349-352. apoyo brindado a Romero por su amigo. El ministro plenipotenciario mexicano sabía de la importancia de esa visita para los intereses mexicanos. El propio Romero ya se había entrevistado con el nuevo secretario de Estado, Frelinghuysen, y aunque no había recibido respuesta oficial, estaba convencido de que el resultado era "muy satisfactorio". La entrevista de Grant con el presidente y con el secretario también lo fue, tanto que Romero consideraba "ya arreglada" la cuestión de Guatemala. ${ }^{45}$

El presidente Justo Rufino Barrios decidió visitar Estados Unidos por varias razones, entre las cuales la no menos importante era entrevistarse personalmente con Matías Romero. Éste, por su parte, no podía olvidar los problemas que había tenido con el liberal guatemalteco en su empresa soconusqueña, sin embargo, obligado a actuar diplomáticamente, consintió en entrevistarse con él. El general Barrios llegó a Estados Unidos el mes de julio de 1882 . Salvo algunas visitas a la capital federal, permaneció en el puerto de Nueva York. Hasta allá fue a visitarlo Matías Romero. Las instrucciones de éste al respecto eran negociar con Barrios y firmar los preliminares de un tratado de límites, sobre la base del reconocimiento guatemalteco de que el Soconusco formaba parte integrante de la república mexicana, y de la no intervención estadunidense en el asun-

45 Carta de Romero a Ignacio Mariscal, Washington, 15 de marzo de 1882, AMR, Copiadores, 38, 376-77. Carta del mismo al mismo, Washing. ton, 28 de marzo de 1882 , $t$ bid., 38, 461-2. También, carta de Romero a Manuel González, Washington, 22 de marzo de 1882, tbid., 38, 396-98. 
to. Lo primero fue fácil de conseguir. El presidente Barrios se mostró dispuesto, desde su llegada, a ceder los derechos que Guatemala creía que le asistían sobre el Soconusco. Resulta muy posible que en este repentino cambio del presidente guatemalteco influyera poderosamente su deseo de unificar a los diversos estados de Centroamérica. En lo que no transigió fue en el asunto de la mediación. Barrios insistió en apelar al arbitraje estadunidense, lo cual Romero aceptó, en un primer momento, siempre y cuando el comisionado estadunidense para realizar la mediación fuera su amigo Uly. sses Grant. ${ }^{46}$

El gobierno de México no aceptó ningún tipo de mediación. No se trataba de la confianza en el general Grant, quien se llamaba a sí mismo "amigo de México", sino de defender la soberanía de un estado que, constitucionalmente, era parte integrante de la federación mexicana. Cualquier tipo de mediación sería considerada por las autoridades mexicanas como una violación a la Constitución. Sin embargo, en Estados Unidos, Justo Rufino Barrios empezó a presionar a Matías Romero. El general guatemalteco iba a partir a Europa y los preliminares de. bían estar firmados antes de su partida. Romero decidió viajar a Nueva York para tener conferencias con Barrios y lograr un acuerdo para los preliminares y, de paso, para buscar apoyo en el general Grant. ${ }^{47}$ En Nueva

46 Romero a Ignacio Mariscal, Washington, 20 de julio de 1882, Archivo Histórico Genaro Estrada (AHGE) de la Secretaría de Relaciones Exteriores, L-E-2018, fojas 1-16.
York, Romero se vio presionado entre las instrucciones que recibía de México, en el sentido de no aceptar ningún arbitraje, y la partida de Barrios, quien se negaba a firmar preliminar alguno si no se asentaba la mediación. Romero creyó encontrar una posible solución en la inclusión de un artículo acerca de que el tratado de límites se basaría en la posesión presente de los terrenos. Es decir, la frontera respetaría las regiones controladas por cada gobierno, y únicamente se "legalizaría" la posesión real. De esta manera, creía Romero, aun cuando se estipulara la presencia de un mediador, ésta sería inútil, pues no habría motivos de discusión. Pese a las instrucciones en contra, que Romero alegó no haber recibido a tiempo, se firmaron los preliminares en Nueva York el 12 de agosto de 1882. En ellos se estipulaban las fechas para la firma del tratado definitivo y las cláusulas de que la frontera se fijaría de acuerdo con la posesión actual, y la mediación de Estados Unidos, en caso de ser necesaria. ${ }^{48}$ El 27 de septiembre, en la ciudad de México, se celebraría la convención de límites, basada en los preliminares neoyorquinos. Sin duda, en la resolución del problema de límites existían otros elementos además de los que podemos aportar aquí acerca de los intereses de Romero y Grant. La unión centroamericana buscada por el presidente Barrios, los intereses del secre-

\footnotetext{
47 Romero a Mariscal, Washington, 3 de agosto de 1882, AHGE, L-E-2017, fojas 103-104.

48 Romero a Mariscal, Nueva York, 12 de agosto de 1882, AHGE, L-E-2018, fojas 143-166. Se incluyen los preliminares.
} 
tario de Estado en la construcción de un canal por Nicaragua -sin negociar con Barrios- y hasta principios de geopolítica norteamericana (evitar a toda costa la influencia europea -0 mexicana- en el istmo) fueron elementos poderosos para evitar una guerra entre México y Guatemala. ${ }^{49}$ Sin embargo, estamos de acuerdo con Brian Connaughton ${ }^{50}$ en el sentido de que la intervención de Estados Unidos, favorable a México en la firma de los preliminares del tratado de límites, también pudo responder a la relación bilateral de ambos países y a las expectativas de empresarios estadunidenses en México. Por lo menos en el caso que venimos estudiando, resulta im. portante esta última posibilidad.

Romero no tenía dudas: la participación del general Ulysses Grant fue asaz importante para solucionar no sólo la cuestión de los preliminares, sino otros asuntos pendientes entre ambas naciones. Para no extendernos más, sólo recordaremos que el general Ulysses Grant fue nombrado comisionado por Estados Unidos, junto con Henry Trescot, para firmar el tratado de reciprocidad comercial entre México y Estados Unidos. Los comisionados

49 Thomas Schoonover resaltó ya la geopolítica en su ponencia "The United States and european interests in mexican guatemalan relations from the 1850 s to 1930 " presentada en el Instituto Mora el 22 de noviembre de 1995. En su comentario a esta ponencia, Mónica Toussaint resaltó la importancia de la unidad centroamericana para Barrios en la firma del tratado con México, lo cual puede probarse con la carta de Francisco Loaeza a Ignacio Mariscal, Guatemala, 13 de abril de 1882, AHGE, L-E-2201, fojas 1-3.

${ }^{50}$ En su comentario a la ponencia de Schoonover. mexicanos fueron Matías Romero y Estanislao Cañedo. El tratado fue firmado en Washington el 20 de enero de 1883. Los grupos proteccionistas en Estados Unidos no aprobaron el tratado. De hecho, en el año electoral de 1883 , tanto el candidato republicano, Blaine, como el demócrata, Grover Cleveland, abanderaron sus campañas en la tarifa proteccionista. Por esto no nos extenderemos más. Únicamente resaltaremos que entre los productos que se admitirían libres de impuestos en México (las listas fueron elaboradas por Matías Romero) se encontraban alambres para telégrafos y de otros tipos, aperos de labranza, casas de madera y hierro, carbón, coches de ferro. carril, locomotoras, máquinas de vapor y otros aparatos para la industria. Elementos necesarios para construir ferrocarriles y líneas telegráficas. Los artículos exportables por México a Estados Unidos, libres de derechos, contaban azúcar, café, carnes, cueros, frutas tropicales, henequén, hule y tabaco, entre otros. ${ }^{51}$ Productos, como hemos dicho antes, típicos del sudeste $y$, por ende, fácilmente transportables en el Ferrocarril Meridional Mexicano, por no recordar los intereses agrícolas de Romero en aquellas regiones.

\section{El SOUTHERn MEXICAN RAILROAD, DOS}

Debió haber sido poco después de que se firmaron los preliminares entre $\mathrm{Ba}$ rrios y Romero, cuando el general Uly. sses Grant fue a visitar al presidente guatemalteco. En esa ocasión, el gene-

${ }^{51}$ Romero, Reciprocidad, 1971, pp. 3-17. 
ral estadunidense obtuvo de Barrios una concesión para construir $250 \mathrm{mi}$ llas de vías férreas en Guatemala. ${ }^{52} \mathrm{Su}$ intención era formar un sistema ferroviario que, partiendo de Centroamérica, llegara hasta Estados Unidos a través de México. Ciertamente la compañía aún no iniciaba la construcción peroel 4 de septiembre Romero, Grant, Work y Ord acordaron que este último vendría a México para iniciar los trabajos. ${ }^{53}$

Desde antes de salir rumbo a Estados Unidos, Matías Romero había informado que los trabajos de reconocimiento de los terrenos por los que pasaría el ferrocarril iban muy avanzados. Es más, logró que Ulysses Grant obtuviera otra concesión. En esta ocasión se trataba de construir un puerto en Antón Lizardo, para que uno de los ramales del ferrocarril encontrara allí un punto para la exportación. Hasta el momento no podríamos explicarnos por qué, si todo iba tan bien y los trabajos iban adelantados, se pidió el 11 de enero una prórroga de seis meses más en los plazos de construcción. ${ }^{54}$ La estancia de Romero en Estados Unidos no facilitó las cosas. En su correspondencia con Blas Balcárcel, socio y representante de la compañía en México, sólo afirmaba que todo iba bien y que pronto se iniciaría la cons-

52 Pletcher, Rails, 1958, p. 164. Según Pletcher la concesión la otorgó Barrios en Estados Unidos el 6 de octubre de 1882, cuando éste ya había regresado de Gran Bretaña.

53 Carta de Romero a Blas Balcárcel, Washington, 6 de septiembre de 1882, AMR, Copiadores, 41, 63. Balcárcel era, por esos días, representante del ferrocarril en México. 801.

54 Romero, "Informe", 1885, t. 3, pp. 796- trucción, pero no hay nada concreto. En septiembre de 1882 Romero se dirigió a Porfirio Díaz para que, a través de sus vínculos, lograra una nueva prórroga para la construcción de las vías. ${ }^{55}$

En realidad, el problema era la falta de fondos para la construcción del ferrocarril. En enero de 1883, Romero logró la promesa del general Ord para gastar hasta dos mil dólares en el reconocimiento de la costa de Antón Lizardo, pues ni las obras del puerto se habían empezado. Como afirmó don Matías, era urgente esa inversión pues de otra manera se perdería la conce. sión. ${ }^{56}$ Algún tiempo después, Ulysses Grant negociaría con el millonario Jay Gould la fusión del Mexican Southern Railroad con la compañía, encabezada por Gould, del Ferrocarril Mexicano Oriental Interoceánico Internacional, que debía construir líneas del Golfo de México a Laredo. De esta manera Grant continuaba su proyecto de integrar las vías férreas desde Centroamérica hasta Estados Unidos, aunque sin duda también lo hacía por la necesidad de apoyo económico. La fusión de las concesiones se llevó a cabo el 14 de mayo de 1883 , y la compañía mantuvo el nombre del Southern Mexican Railroad, o Ferrocarril Meridional Mexicano. ${ }^{57}$

Recordemos que, por la época, se empezaban a manifestar en Estados Unidos los síntomas de una falta de

55 Carta de Romero a Porfirio Díaz, Washington, 13 de septiembre de 1882, AMR, Copiadores, $41,515$.

56 Carta de Romero a Blas Balcárcel, Washington, 5 de enero de 1883, AMR, Copiadores, 41,515 .

${ }^{57}$ El contrato de fusión y la aprobación del Congreso, en Memoria, 1887, t. 2, pp. 510-513. 
liquidez en los mercados de capitales, preludio de una recesión económica. Sin duda ese elemento fue tremendamente importante para explicarnos las carencias de fondos de la compañía del Mexican Southern Railroad. También debemos considerar la gran cantidad de inversiones que emprendió Ulysses Grant por esas fechas, pues además del ferrocarril y el puerto en Antón Lizardo, fundó la Compañía del Cable Submarino Interoceánico, que debía tender cables telegráficos entre Estados Unidos, Cuba y Yucatán, y de alli al Sudeste y Centroamérica. De la misma manera presidió una compañía que promovía la construcción de canales en Centroamérica, donde también intentó construir ferrocarriles. Por último, el viejo general había invertido en una compañía dirigida por su hijo, Grant \& Ward, dedicada a la especulación de valores en Nueva York. Grant $\&$ Ward fue sorprendida en prácticas ilegales, como la rehipotecación, por lo cual perdió confianza y terminó en quiebra. ${ }^{58}$

Para colmo, el tratado de reciprocidad comercial entre México y Estados Unidos no era aprobado. Hemos visto cómo los productos comerciables de Estados Unidos a México, según el tratado, eran importantes para la construcción de ferrocarriles. En ese senti-

58 McFelly, Grant, 1982, pp. 489-492. Desde mediados de 1882 había rumores de que Grant habia perdido toda su fortuna en la bolsa, y si bien aseguró a Romero que eran falsos, tampo. co quiso desmentirlos; despacho de Matías Romero a Ignacio Mariscal, Washington, 15 de abril de 1882, AHGE, Archivo de la Embajada de México en Estados Unidos de América, t. 55, despacho 128, pp. 205-207. do, el Mexican Southern Railroad, sin subsidios, dependía de la ratificación en el Congreso de ese tratado. ${ }^{59}$ Romero tenía esperanzas en la aprobación, que nunca llegó. Finalmente, la compañía perdió la concesión el 29 de mayo de 1885, pues no había "constancia de que diera principio a los trabajos de construcción". ${ }^{60}$

\section{CONCLUSIÓN}

Todavía tardaron muchos años en la construcción de un ferrocarril en Chiapas, aunque el proceso de modernización (en la explotación) y centralización en aquella región se llevó a cabo. Lo mismo ocurrió en el resto del país. Esta modernización fue impulsada principalmente por inversionistas extranjeros, pero hemos visto que, en realidad, los subsidios con que el gobierno mexicano acompañaba las concesiones eran muy importantes. Un ferrocarril sin subsidios no pudo ser construido (harían falta más estudios de caso para generalizar estas conclusiones y mostrar sus límites). Lo que sí resulta claro es que el proyecto liberal encauzado por los políticos porfirianos logró la modernización del país. Es decir, el proyecto individualista, del enriquecimiento de particulares, logró su objetivo: promover la inversión en México y desarrollar ciertas áreas productivas. ${ }^{61}$ Romero no escapó a

59 Carta de Romero a Balcárcel, Washington, 19 de febrero de 1883, AMr, Copiadores, 41, 770 .

60 Memoria, 1887 , t. 2, pp. $589-590$.

61 Algunas consideraciones acerca de los re. publicanos liberales mexicanos, en Brading, 


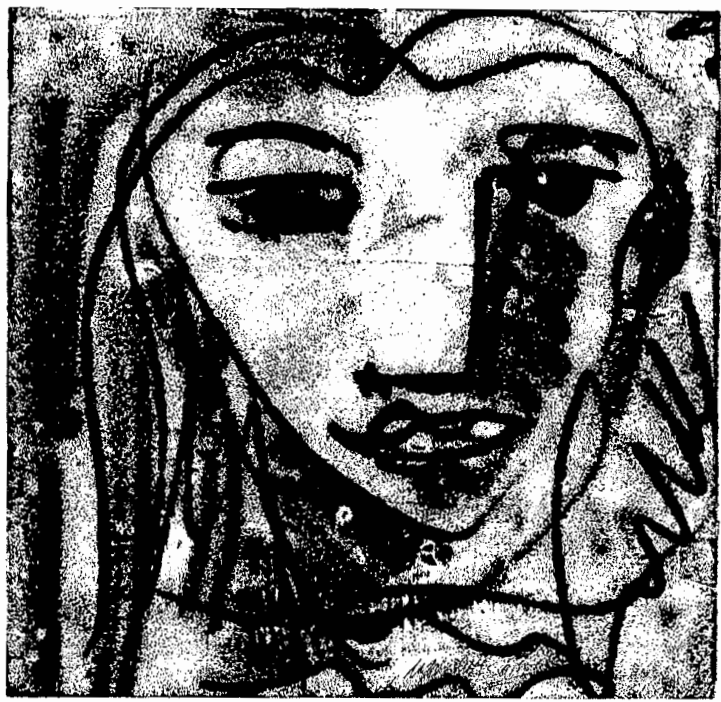

este impulso. En una fecha tan tardía como 1892 aún creía en las bondades del liberalismo. Cuando algunos delegados de los trabajadores del valle de México rogaron la intervención del gobierno federal para lograr algún aumento en sus raquíticos salarios, Romero publicó una "Carta a los delegados de los trabajadores de las fábricas del valle de México", en el Diario Oficial del 17 de diciembre de $1892 .{ }^{62}$ En esa carta, alegaba que el gobierno tenía "por norma la ley, y por aspiración la justicia", pero también tenía vedada "toda injerencia directa en las

Orbe, 1993, pp. 710-721. Brading sigue de cerca el análisis sobre el republicanismo clásico y el liberalismo de Pocock, Machiavelan, 1975.

${ }^{62}$ Está reproducida en Historia, 1984, vol. 2, pp. 380-383. relaciones de patrón a obreros", aunque sus salarios fueran verdaderamente miserables. Esta actitud podría parecernos la de un capitalista despiadado e inhumano, mas para Romero ésa era la única manera de lograr el progreso de México y, por añadidura, para esos mismos trabajadores:

México tiene por la naturaleza ventajas especiales para la producción de ciertos frutos, y si los capitales y las energías del país se destinaran a producirlos, la situación del país sería ahora mucho más favorable de la que actualmente tenemos. ${ }^{63}$

Desde una óptica liberal, el desarrollo del país y, pues, el bienestar de

${ }^{63}$ Ibid., p. 383. 
todos sus habitantes, sólo se podía conseguir gracias a la actividad productiva de cada uno de los ciudadanos. El entiquecimiento de algunos de éstos no era malo o injusto sino el primer paso para llegar a la prosperidad general. Por eso, Romero usó sus puestos públicos y relaciones políticas para beneficiar sus intereses privados. Esta práctica, que podríamos calificar de corrupta, no lo era desde su peculiar punto de vista. Al contrario: su empresa particular resultaba útil para la sociedad. La solución de conflictos diplomáticos y el establecimiento de tratados comerciales daban prueba de las rectas intenciones del promotor del ferrocarril. Este mismo permitiría la salida de los productos del sudeste, los que vendidos en Estados Unidos permitirían el desarrollo de la región. El ferrocarril integraría también a Chiapas con el resto del país, lo cual protegería mejor la soberanía nacional en aquella frontera al facilitar el transporte de tropas. En fin, toda aquella prosperidad y desarrollo material perseguido por los liberales mexicanos alcanzarían al fin el progreso "moral" de la población. Matías Romero era un republicano $-\mathrm{y}$ no sólo por su apoyo a Juárez-: su ética establecía que el ciudadano trabaja para la república, lo mismo que para sí.

No podriamos hacer extensivas nuestras consideraciones a todos los miembros de la elite porfiriana, y mucho menos a todos los hombres que se han encargado de dirigir nuestro derrotero político y económico. Nosotros intentamos mostrar sólo un caso y resaltar en él un problema: las relaciones entre los intereses privados y la acción diplomática, es decir, la posibilidad de que el discurso de algunos de los actores políticos mexicanos no sea sólo una pieza justificativa de actos egoístas, sino parte de un proyecto público, bien que, desde luego, no se excluya el beneficio privado.

\section{FUENTES: MANUSCRITOS}

-Archivo Histórico Genaro Estrada de la Secretaría de Relaciones Exteriores:

-Archivo de la Embajada de México en los Estados Unidos: tomo 55.

-Legajos encuadernados: L-E-2017, L-E2018, L-E-2201.

-Archivo de Matías Romero (AMR). Banco de México:

-Copiadores. Correspondencia despachada: volúmenes 37-41.

-Correspondencia recibida (micropelícula en el Instituto Mora): rollos 37 y 38.

-National Archives. Washington (micropelícula en el Instituto de Investigaciones Históricas de la Universidad Nacional Autónoma de México):

-Despachos enviados por los ministros plenipotenciarios en México al Departamento de Estado de los Estados Unidos (M 97): rollos 67-72.

-Instrucciones de los secretarios de Estado a la legación de los Estados Unidos en México (M 77): rollo 116.

-Universidad Iberoamericana:

-Archivo Porfirio Díaz: legajo 7, caja 1.

\section{IMPRESOS}

\section{a) De Matías Romero}

-"Carta a los delegados de los trabajadores del valle de México", en Ernesto de la Torre, Moisés González Navarro y Stanley Ross (comps.), Historia Documental de Méxi- 
co, Instituto de Investigaciones Históricas, México, Universidad Nacional Autónoma de México, 1984, vol. 2, pp. 380-383.

-Cultivo del café en la costa meridional de Chiapas, Imprenta del Gobierno en Palacio a cargo de José María Sandoval, México, 1875, 3a. ed. (Hay edición facsímil).

"Cultivo del café en Oaxaca y exportación de azúcar mexicano [sic.]", en Textos escogidos, Instituto Mexicano del Café, Secretaría de Agricultura y Recursos Hidráulicos, México [1988]).

-Expediente de la Secretaría de $\mathrm{Ha}$ cienda respecto a las medidas propuestas y acordadas para impulsar el desarrollo de los elementos de la riqueza del departamento de Soconusco, 1870-1871, Imprenta del Gobierno en Palacio a cargo de José María Sandoval, México, 1871.

-Importancia del cultivo del hule en el porvenir de la república, Secretaría de Fomento, México, 1898, 3a. ed.

-Informe de Matías Romero al gobernador del Estado de Oaxaca, respecto de la compañía que organizó para construir el ferrocarril de Oaxaca y del traspaso que hizo de su concesión de 25 de agosto de 1880, Imprenta del estado en el ex obispado, dirigida por Ignacio Candiani, Oaxaca, 1881.

-"Refutación de las inculpaciones hechas al ciudadano Matías Romero por el gobierno de Guatemala", en Matías Romero: Textos escogidos, edición y prólogo de Josefina Fernández MacGregor, Consejo Nacional para la Cultura y las Artes, México, 1992 (Cien de México).

-Mexican lobby. Matías Romero in Washington, 1861-1867, trad. y edición de Thomas y Ebba Schoonover, The University Press of Kentucky, Lexington, 1986.

-Reciprocidad comercial entre México $y$ los Estados Unidos (el tratado comercial de 1883), prólogo de Romeo Flores Caballero, Publicaciones del Banco Nacio- nal de Comercio Exterior, México, 1971. -Refutación de las inculpaciones hechas al ciudadano Matías Romero por el gobierno de Guatemala, Imprenta Políglota del C. Ramiro Ponce de León, México, 1876.

\section{b) Otras fuentes primarias}

- Diario de los debates de la Cámara de Diputados. $10^{a}$ Legislatura Constituctonal de la Unión, Tipografía Literaria de Filomeno Mata, México, 1881.

-Diario Oficial, México, 1881.

-González, Manuel, Discurso pronunciado por el presidente de los Estados Unidos Mexicanos ante el Congreso de la Unión, el 1 de Abril de 1881, s. p. i., pp. 57-66.

-Romero, "Informe del representante sobre los trabajos de reconocimiento y trazos ejecutados por la compañía [del Southern Mexican Railroad]" e "Informe de la Sección 3a.", en Memoria presentada al Congreso de la Unión, por el secretario [...] de Fomento [...]. Correspondiente a los años transcurridos de dictembre de 1877 a diciembre de 1882, Oficina Tipográfica de la Secretaría de Fomento, México, 1885, 3 tomos.

-Memoria presentada al Congreso de la Unión, por el secretario [...] de Fomento [...]. Correspondiente a los años transcurridos de enero de 1883 a junio de 1885, Oficina Tipográfica de la Secretaría de Fomento, México, 1887, 2 tomos.

\section{BIBLIOGRAFIA}

-Benjamin, Thomas Louis, El camino a Leviatán. Chiapas y el Estado mexicano, 1891-1947, trad. de Sara Sefchovich, Consejo Nacional para la Cultura y las Artes, México, 1980 (Colección Regiones).

-Berstein, Harry, Matías Romero, 1837 1898 , trad. de Margarita Montellano, Fon- 
do de Cultura Económica, México, 1982 (Sección de Obras de Historia).

-Brading, David, Orbe indiano. De la monarquía católica a la república criolla, 1492-1867, trad. de Juan José Utrilla, Fondo de Cultura Económica, México, 1993 (Sección de Obras de Historia).

-Coatsworth, John, "El impacto económico de los ferrocarriles en una economía atrasada", Los orígenes del atraso. Nueve ensayos de historia económica de Méxtco en los siglos XVIII $y$ XIX, trad. de Juan José Utrilla, Alianza Editorial, México, 1992 (Raíces y razones).

-Cosío Villegas, Daniel, "La aventura de Matías", Historia Mexicana, vol. vII, núm. 1, julio-septiembre de 1958, México. Historia moderna de México. Volumen $v$. El porfiriato. La vida política exterior. Primera parte, Editorial Hermes, México, 1983, 3a. ed.

-Escalante, Fernando, Ciudadanos imaginarios. Memorial de los afanes $y$ desventuras de la virtud y apología del vicio triunfante en la república mexicana -tratado de moral pública-, Centro de Estudios Sociológicos-El Colegio de México, México, 1993.

-González, Cristina, "Reconstrucción y nueva sociedad, 1865.1895", en Estados Unidos de América. Síntesis de su historia, Instituto Mora/Alianza Editorial, México, 1985 , t. 9.

-Gurza, Gerardo, El tratado de reciprocidad comercial. Catálogo de documentos en el Archivo de la Embajada de México en los Estados Unidos de América (1882-1888), Consejo Nacional de Ciencia y Tecnología/Instituto Mora/Instituto de Investigaciones Históricas-Universidad Nacional Autónoma de México, México, 1995 (Colección Carlos Bosch García).

-Hale, Charles A., La transformación del liberalismo en México a fines del Siglo $X I X$, trad. de Purificación Jiménez, Vuelta, México, 1991 (La Reflexión).

-Hirschmann, Albert O., Las pasionesy los intereses. Argumentos políticos en favor del capitalismo antes de su triunfo, trad. de Eduardo L. Suárez, Fondo de Cultura Económica, México, 1978.

-Katz, Friedrich, "La república restaurada y el Porfiriato", Ensayos mexicanos, trad. de Eliane Cazenave-Tapie, Alianza Editorial, México, 1994, pp. 159-245 (Raíces y razones).

-McFelly, William, Grant. A biography, W. W. Norton \& Company, Nueva York, 1982.

-Pletcher, David M., Rails, mines and progress. Seven american promoters in Mexico, 1867-1911, American Historical Association, Cornell University Press, Ithaca, 1958.

-Pocock, John A. G., The machiavelan moment, Princeton University Press, Princeton y Londres, 1975.

-Reichley, James P., The life of the parties. A history of american political parties, The Free Press, Nueva York, 1992.

-Riguzzi, Paolo, "México próspero: las dimensiones de la imagen nacional en el porfiriato", Historias, núm. 20, abril-septiembre de 1988, México.

-Schoonover, Thomas, "The United States and european interests in mexicanguatemalan relations from the 1850 s to $1930^{\prime \prime}$, conferencia presentada en el Instituto Mora, 22 de noviembre de 1995. Comentarios de Mónica Toussaint y Brian Connaughton.

-Sepúlveda, César, "Historia y problemas de los límites de México II. La frontera sur", Historia Mexicana, vol. vIII, núm. 2, octubre-diciembre de 1958, México, pp. 145-174.

-Valadés, José C., El Porfirismo. Historia de un régimen. Tomo l. El nacimiento (1876-1884), Universidad Nacional Autónoma de México, México, 1987, 2a. ed.

-Zorrilla, José, Relaciones de México con la República de Centro América y con Guatemala, Editorial Porrúa, México, 1984, 980 pp. (Biblioteca Porrúa). 